Universidade Tecnológica Federal do Paraná - UTFPR

Campus Ponta Grossa - Paraná - Brasil

ISSN: 1981-3686/v. 04, n. 01: p. 10-18, 2010

D.O.I.: $10.3895 / \mathrm{S} 1981-36862010000100002$
Revista Brasileira deTecnologia

Agroindustrial

\title{
MICROFLORA ASSOCIADA AOS GRÃOS DE CAFÉ EM COCO E BENEFICIADO PRODUZIDOS NO PARANÁ.
}

\section{IDENTIFICATION OF MICROFLORA ASSOCIATED TO COFFEE GRAINS IN COCONUT AND BENEFICED PRODUCED INTO THE PARANÁ STATE.}

\author{
Carla Adriana Pizarro Schmidt ${ }^{1}$; Édison Miglioranza ${ }^{2}$; Martin Homechin ${ }^{3}$ \\ ${ }^{1}$ Universidade Tecnológica Federal do Paraná - UTFPR - Medianeira - Brasil carlaschmidt@ utfpr.edu.br \\ ${ }^{2,3}$ Universidade Estadual de Londrina - UEL - Londrina - Brasil emiglior@ uel.br
}

\section{Resumo}

A contaminação e a colonização de grãos de café por microrganismos podem comprometer a qualidade da bebida, sendo assim de grande importância avaliar qualitativamente esse produto. $O$ objetivo do presente estudo foi identificar os microorganismos associados aos frutos de café em coco e grãos beneficiados colhidos em lavouras implantadas em solos originados do basalto e do arenito Caiuá. Foi empregado o método do papel de filtro, Blotter Test e os fungos identificados com base nas características morfológicas observadas sob microscópios estereoscópico e óptico. $O$ delineamento utilizado foi o inteiramente casualizado em esquema fatorial $\left(\begin{array}{lll}2 & x\end{array}\right)$ dois solos (basálticos $x$ solos arenosos) $x$ quatro processamentos (beneficiado e coco ambos com e sem assepsia), totalizando oito tratamentos. Para cada tratamento foram avaliadas 10 repetições com 20 sementes cada. Nas amostras de solos de origem basáltica foram observados maiores percentuais de fungos como Alternaria sp., Aspergillus sp., Aspergillus niger, Aspergillus ochraceus, Aspergillus flavus e Colletotrichum sp. O único microorganismo que teve prevalência para cafés dos solos arenosos foi a Rhizoctonia sp. De modo geral o beneficiamento e a assepsia das sementes, com hipoclorito de sódio $0,5 \%$ por 1 minuto, reduziram a incidência de microorganismos.

Palavras-chave: Coffea arabica; microbiologia; fungos filamentosos.

\section{Introdução}

A qualidade da bebida de café sempre foi preocupação dos pesquisadores e sofre influência da presença de microrganismos nos grãos utilizados como matéria prima para obtenção da infusão. Um dos primeiros relatos dessa perda de qualidade foi o de Camargo em 1936, o qual correlacionou o gosto ruim do café com a população microbiana presente nos grãos.

Em 1941, Krug destacou que, as piores bebidas são as provenientes de frutos com maiores percentuais de microrganismos, principalmente fungos, podendo ser encontrados mesmo no interior dos grãos e observados em cortes sob o microscópio. A maior parte do café brasileiro é seco pelo processo denominado de via seca ou café em coco, onde a mistura de frutos colhidos é levado ao 
terreiro para secagem. Após uma secagem parcial o café é amontoado durante as noites para que ocorra equilíbrio de umidade entre os grãos e novamente espalhados no terreiro até secagem completa $(11-12 \%)$.

Dentre os fatores que influem na qualidade do café, a incidência de microrganismos nas fases de pré e pós-colheita tem sido um dos principais fatores envolvidos. Os frutos sempre estão expostos a uma diversidade de microrganismos, a exemplo de leveduras, fungos, bactérias, que sob condições favoráveis se desenvolvem e infectam os grãos. Dentre os microrganismos que compõem a microbiota do café, os fungos filamentosos representam o grupo que pode causar maior dano, com comprometimento da qualidade (CARVALHO, 1997).

Tendo em vista a relação entre a contaminação por microrganismos e a qualidade do café, este estudo foi realizado buscando quantificar a microflora presente em grãos de café colhidos em lavouras do Paraná, cultivadas em solo das regiões do basalto e arenito Caiuá.

\section{Material e métodos}

Foram avaliadas amostras de café 'IAPAR 59' colhidas em sítios e fazendas produtoras de café localizadas em sete cidades paranaenses (Lupionópolis, Centenário do Sul, Miraselva, Prado Ferreira, Astorga, Munhoz de Melo e Londrina), municípios aptos ao cultivo (MITIDIERI, 2007) e que, com exceção de Londrina, possuem os dois tipos de materiais de origem dos solos (basalto e arenito). A colheita nesses municípios, em propriedades próximas, mas dispostas em solos arenosos e argilosos respectivamente visou reduzir as possíveis diferenças impostas pelo clima no produto.

Destas amostras 15 foram coletadas em solos Basálticos e 15 em solos de arenito. A média de altitude dos locais foi de 630 metros para os solos de basalto (valores entre 498 metros e 710 metros acima do nível do mar) e 524 metros para os solos de arenito (valores entre 390 metros e 647 metros acima do nível do mar). A colheita das amostras de café foi manual no período de 15 de março a 12 de abril de 2007. Deu-se preferência para os frutos localizados na parte média da planta, e procurou-se colher frutos que estivessem em sua maioria no estágio cereja. A secagem foi ao sol em terreiro convencional localizado em uma das propriedades $\left(23^{\circ} 30^{\prime} \mathrm{S}\right.$ e $\left.51^{\circ} 17^{\prime} \mathrm{W}\right)$ em altitude de $710 \mathrm{~m}$. As amostras em coco foram estocadas em câmara fria e seca da Universidade Estadual de Londrina, em Londrina - PR.

Após preparou-se uma mistura com pesos idênticos do café em coco para cada uma das propriedades obtendo-se duas amostras compostas distintas, uma de café proveniente do arenito e outra proveniente do basalto, de modo a isolar os efeitos dos solos e, minimizar características isoladas de cada propriedade e tratos culturais que pudessem interferir na qualidade final do produto sem ter relação com o fator solo. O beneficiamento foi realizado em descascador de café manual, 
próximo aos dias de realização das análises, no mês de outubro, objetivando melhor proteção dos grãos durante o armazenamento.

A avaliação microbiológica dos grãos foi realizada no Laboratório de Fitopatologia de Universidade Estadual de Londrina, no mês de outubro de 2007. Foi utilizado o método do blotter test (papel de filtro) segundo Neergard (1977), e consistiu da incubação dos frutos (em coco e beneficiados) em placas de Petri, contendo duas folhas de papel de filtro esterilizadas e umedecidas com água destilada e esterilizada, incubadas por sete dias, sob condições de temperatura controlada $\left(23 \pm 1{ }^{\circ} \mathrm{C}\right)$ em regime alternado de luz (12/12 horas).

Foram avaliadas 10 repetições com 20 grãos de café cada. As avaliações foram realizadas no sétimo dia da incubação com observação dos microrganismos presentes desenvolvidos sobre os frutos e sementes, sob microscópio estereoscópico e a identificação com base na visualização das estruturas, colônias e esporos. Nos casos duvidosos foram preparadas lâminas para observação ao microscópio ótico baseada na classificação adotada por Barnett e Hunter (1972). Adotado esse procedimento, foi anotada a quantidade de frutos contaminados com cada gênero de fungo identificado e posteriormente os números foram transformados para percentuais de contaminação.

Foram avaliados grãos em coco e beneficiados, ambos com e sem assepsia. Para todos os tratamentos foram utilizadas 10 repetições com 20 sementes cada. A desinfestação superficial das sementes foi feita, utilizando-se solução de hipoclorito de sódio a $0,5 \%$, por meio de imersão por um minuto.

A análise estatística foi feita por meio do delineamento inteiramente casualizado em esquema fatorial dois solos (basálticos $\mathrm{x}$ solos arenosos) $\mathrm{x}$ quatro processamentos (beneficiado e coco, ambos com e sem assepsia), totalizando oito tratamentos, com 10 repetições, de 20 sementes cada. Os dados dos percentuais de incidência dos fungos nos grãos de café foram transformados em arco seno da raiz de $(n+1 / 100)$ para análise de variância. Para comparação das médias, empregou-se o teste de Tukey $(\mathrm{p}<0,05)$.

\section{Resultados e discussão}

Os maiores percentuais de contaminação foram observados nas amostras de café em coco sem assepsia das amostras colhidas em solos basálticos (Tabela 1). Se considerarmos apenas o fator textura do solo, podemos observar que o café proveniente de solos basálticos apresentou uma quantidade maior de microorganismos, com diferença significativa para os fungos: Alternaria $s p$., Aspergillus sp., Aspergillus niger, Aspergillus ochraceus, Aspergillus flavus e Colletotrichum sp. O único microrganismo com comportamento diferente foi a Rhizoctonia sp. que apresentou uma 
contaminação maior nas amostras provenientes de solos arenosos. Para os demais microrganismos não foram observadas diferenças significativas entre os solos.

Tabela 1 - Microrganismos associados a grãos de café de amostras provenientes das regiões de basalto e arenito, beneficiados e em coco, com e sem assepsia.

\begin{tabular}{|c|c|c|c|c|c|c|c|c|}
\hline \multirow{3}{*}{ Microrganismos } & \multicolumn{4}{|c|}{ Basalto } & \multicolumn{4}{|c|}{ Arenito } \\
\hline & \multicolumn{2}{|c|}{ Coco } & \multicolumn{2}{|c|}{ Beneficiado } & \multicolumn{2}{|c|}{ Coco } & \multicolumn{2}{|c|}{ Beneficiado } \\
\hline & $\begin{array}{c}\text { Sem } \\
\text { Assep. }\end{array}$ & $\begin{array}{c}\text { Com } \\
\text { Assep. }\end{array}$ & $\begin{array}{c}\text { Sem } \\
\text { Assep. }\end{array}$ & $\begin{array}{c}\text { Com } \\
\text { Assep. }\end{array}$ & $\begin{array}{c}\text { Sem } \\
\text { Assep. }\end{array}$ & $\begin{array}{c}\text { Com } \\
\text { Assep. }\end{array}$ & $\begin{array}{c}\text { Sem } \\
\text { Assep. }\end{array}$ & $\begin{array}{c}\text { Com } \\
\text { Assep. }\end{array}$ \\
\hline Alt & $10,68^{\mathrm{aA}}$ & $10,23^{\mathrm{aA}}$ & $5,74^{\text {bA }}$ & $5,74^{\mathrm{bA}}$ & $8,99^{\mathrm{a} A}$ & $6,96^{\mathrm{abB}}$ & $5,74^{\text {bA }}$ & $5,74^{\text {bA }}$ \\
\hline Asp & $6,98^{\mathrm{aA}}$ & $5,74^{\mathrm{bA}}$ & $5,74^{\mathrm{bA}}$ & $5,74^{\mathrm{bA}}$ & $5,74^{\mathrm{aB}}$ & $5,74^{\mathrm{aA}}$ & $5,74^{\mathrm{aA}}$ & $5,74^{\mathrm{aA}}$ \\
\hline Aspergillus & $12,69^{\mathrm{aA}}$ & $6,00^{\mathrm{bA}}$ & $6,11^{\mathrm{bB}}$ & $5,87^{\mathrm{bA}}$ & $7,63^{\mathrm{aB}}$ & $6,00^{\mathrm{bA}}$ & $8,05^{\mathrm{aA}}$ & $5,74^{\mathrm{bA}}$ \\
\hline Aspergillus & $11,51^{\mathrm{aA}}$ & $5,74^{\mathrm{cA}}$ & $9,47^{\mathrm{bA}}$ & $6,11^{\mathrm{cB}}$ & $7,06^{\mathrm{abB}}$ & $5,87^{\mathrm{bA}}$ & $7,08^{\mathrm{abB}}$ & $7,57^{\mathrm{aA}}$ \\
\hline Aspe & $14,92^{\mathrm{aA}}$ & $6,22^{\mathrm{bA}}$ & $5,74^{\text {bA }}$ & $5,74^{\mathrm{bA}}$ & $9,60^{\mathrm{aB}}$ & $5,87^{\mathrm{bA}}$ & $5,98^{\mathrm{bA}}$ & $5,74^{\text {bA }}$ \\
\hline Chaet & $5,74^{\mathrm{aA}}$ & $5,74^{\mathrm{aA}}$ & $5,74^{\mathrm{aA}}$ & $5,74^{\mathrm{aA}}$ & $6,53^{\mathrm{aA}}$ & $5,74^{\mathrm{bA}}$ & $5,74^{\mathrm{bA}}$ & $5,74^{\mathrm{bA}}$ \\
\hline Clados & $13,36^{\mathrm{aA}}$ & $7,00^{\mathrm{bcA}}$ & $8,93^{\mathrm{bA}}$ & $5,74^{\mathrm{cA}}$ & $14,11^{\mathrm{aA}}$ & $7,14^{\mathrm{bA}}$ & $6,24^{\mathrm{bB}}$ & $5,67^{\mathrm{bA}}$ \\
\hline Colletc & & $12,38^{\mathrm{aA}}$ & $5,74^{\mathrm{cA}}$ & & & & $5,74^{\mathrm{bA}}$ & $5,74^{\mathrm{bA}}$ \\
\hline Fusariur & $7,61^{\mathrm{bB}}$ & $12,45^{\mathrm{aA}}$ & $6,96^{\mathrm{bA}}$ & $6,11^{\mathrm{bA}}$ & $11,44^{\mathrm{aA}}$ & $10,85^{\mathrm{aA}}$ & $6,81^{\mathrm{bA}}$ & $6,24^{\mathrm{bA}}$ \\
\hline Мисо &, $09^{\mathrm{aA}}$ & $5,87^{\mathrm{aA}}$ & $6,54^{\mathrm{aA}}$ & $6,57^{\mathrm{aA}}$ & $6,08^{\mathrm{aA}}$ & $5,74^{\mathrm{aA}}$ & $5,87^{\mathrm{aA}}$ & $6,74^{\mathrm{aA}}$ \\
\hline Penicillium & $7,62^{\mathrm{aA}}$ & $6,59^{\mathrm{bA}}$ & $6,00^{\mathrm{bA}}$ & $6,00^{\mathrm{bA}}$ & $7,06^{\mathrm{aA}}$ & $6,24^{\mathrm{bA}}$ & $6,26^{\mathrm{bA}}$ & $5,74^{\mathrm{bA}}$ \\
\hline Rhizop & $7,49^{\mathrm{aA}}$ & $5,98^{\mathrm{aA}}$ & $7,73^{\mathrm{aA}}$ & $5,74^{\mathrm{aA}}$ & $6,16^{\mathrm{aA}}$ & $5,74^{\mathrm{aA}}$ & $6,00^{\mathrm{aA}}$ & $6,71^{\mathrm{aA}}$ \\
\hline Rhizo & $74^{\mathrm{aA}}$ & $5,74^{\mathrm{aB}}$ & $5,74^{\mathrm{aA}}$ & $5,74^{\mathrm{aA}}$ & $5,74^{\mathrm{bA}}$ & $13,99^{\mathrm{aA}}$ & $5,74^{\mathrm{bA}}$ & $5,74^{\mathrm{bA}}$ \\
\hline Trichodern & $5,74^{\mathrm{aA}}$ & $5,74^{\mathrm{aA}}$ & $5,74^{\mathrm{aA}}$ & $6,11^{\mathrm{aA}}$ & $5,74^{\mathrm{aA}}$ & $5,74^{\mathrm{aA}}$ & $6,11^{\mathrm{aA}}$ & $5,74^{\mathrm{aA}}$ \\
\hline Fungo & $5,74^{\mathrm{bA}}$ & $5,74^{\mathrm{bA}}$ & $9,09^{\mathrm{aA}}$ & $10,42^{\mathrm{aA}}$ & $5,74^{\mathrm{bA}}$ & $5,74^{\mathrm{bA}}$ & $7,45^{\mathrm{aA}}$ & $8,90^{\mathrm{aA}}$ \\
\hline Bactérias & $5,74^{\mathrm{bA}}$ & $6,70^{\mathrm{aA}}$ & $5,74^{\mathrm{bA}}$ & $5,74^{\mathrm{bA}}$ & $5,74^{\mathrm{bA}}$ & $6,81^{\mathrm{aA}}$ & $5,74^{\mathrm{bA}}$ & $5,74^{\mathrm{bA}}$ \\
\hline
\end{tabular}

Obs. Valores transformados arco seno da raiz de $(n+1 / 100)$. Letras minúsculas indicam diferença significativa entre os tratamentos dentro do fator solos e letras maiúsculas indicam diferença entre tratamentos iguais em solos diferentes.

As maiores incidências foram de bolores do gênero Aspergillus sp. (Tabela 1 e Figura 1).

Figura 1 - Incidência de Fungos do gênero Aspergillus em cafés de diferentes texturas de solos, beneficiados ou não e com e sem assepsia nos diversos tratamentos avaliados apresentados na seguinte ordem: BCSA (Basalto Coco Sem Assepsia), BCCA (Basalto Coco Com Assepsia), BBSA (Basalto Beneficiado Sem Assepsia), BBCA (Basalto Beneficiado Com Assepsia), ACSA (Arenito Coco Sem Assepsia), ACCA (Arenito Coco Com Assepsia), ABSA (Arenito Beneficiado Sem Assepsia), ABCA (Arenito Beneficiado Com Assepsia).

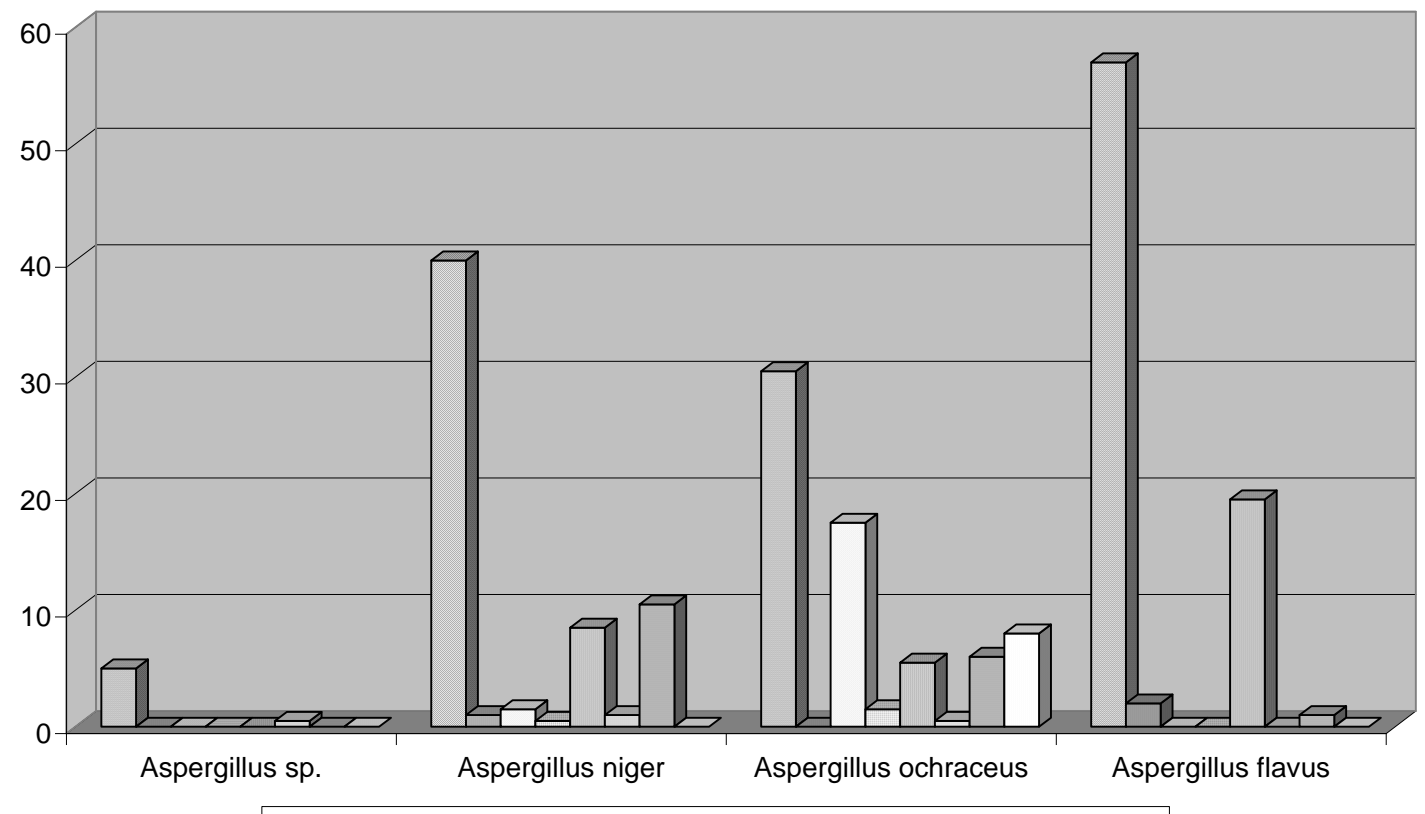

$\square$ BCSA $\square$ BCCA $\square$ BBSA $\square$ BBCA $\square$ ACSA $\square$ ACCA $\square$ ABSA $\square$ ABCA 
Esse resultado é semelhante ao encontrado por Silva et al. (2008), que ao avaliarem $C$. arabica 'Acaiá', cultivado no estado de Minas Gerais, também observaram uma quantidade de Aspergillus sp. superior aos dos gêneros Penicillium sp., Fusarium sp. e Cladosporium sp. Fungos dos gêneros Aspergillus sp., Fusarium sp. e Penicillium sp. têm se destacado como promotores de alteração de características organolépticas do café e produtores de toxinas que prejudicam a saúde do consumidor (PEREIRA, 2002).

Segundo Chalfoun e Carvalho, (1997) várias espécies de fungos como: Fusarium sp., Cladosporium sp., Coletotrichum sp., Penicillium sp., Trichoderma sp. e Gliocladium sp. incidem sobre os frutos do cafeeiro no terreiro, acelerando o processo de fermentação, muitas vezes indesejável. Um dos sérios problemas causado pela secagem do café em terreiros é justamente a sua contaminação por fungos. A secagem se processa mais lentamente em virtude das camadas do pericarpo do fruto o que faz com que os grãos permaneçam úmidos por mais tempo, aumentando o período de predisposição para o desenvolvimento dos microorganismos. Bitancourt (1957), constatou que fungos do gênero Colletotrichum sp. e formadores de bolores verdes do gênero Penicillium sp., entre outros, são abundantes nas diferentes etapas do preparo do café, podendo ocorrer na lavoura e no terreiro durante a secagem. A contaminação por Aspergillus sp. e produção de micotoxinas pode ocorrer antes mesmo da colheita (LACEY, 1994).

Pimenta e Vilela (2001), verificaram que podem ser encontrados diferentes porcentagens médias de ocorrência de Aspegillus sp, Cladosporium sp, Fusarium sp e Penicilium sp. em grãos de café, em cinco diferentes tempos de amontoa dos frutos no terreiro antes da secagem e, os valores por eles encontrados são próximos aos do presente trabalho (Tabela 1 e Figuras 1 e 2), para esses microrganismos nos cafés fermentados durante sete dias.

Nos frutos colhidos no estádio de maturação cereja, estudados por Pimenta e Chaufoun (2001), foi observada a maior ocorrência dos fungos dos gêneros Aspergillus sp., Penicillium sp, Fusarium sp. e Cladosporium sp., no café em coco, e os autores sugeriram que nutrientes como açúcares e pectinas, presentes na casca e na mucilagem servem como substrato para o desenvolvimento desses microorganismos; e que o beneficiamento pode contribuir para redução das contaminações, situação constatada no presente trabalho (Tabela 1 e Figuras 1 e 2).

Os fungos do gênero Cladosporium sp., que comumente ocorrem em frutos do cafeeiro, não se desenvolvem durante a secagem no terreiro (BITANCOURT, 1957), isso sugere que a incidência desse microrganismo nos cafés estudados nesse trabalho tenha sido proveniente do cultivo, sem relação com a colheita ou com o ambiente de secagem (Tabela 1 e Figura 2). Não foi observada diferença significativa entre os níveis de Cladosporium $s p$ nas duas diferentes texturas de solos dentro dos mesmos tratamentos. 
Figura 2 - Porcentagens médias dos principais Fungos contaminantes de café nos diversos tratamentos avaliados apresentados na seguinte ordem: BCSA (Basalto Coco Sem Assepsia), BCCA (Basalto Coco Com Assepsia), BBSA (Basalto Beneficiado Sem Assepsia), BBCA (Basalto Beneficiado Com Assepsia), ACSA (Arenito Coco Sem Assepsia), ACCA (Arenito Coco Com Assepsia), ABSA (Arenito Beneficiado Sem Assepsia), ABCA (Arenito Beneficiado Com Assepsia).

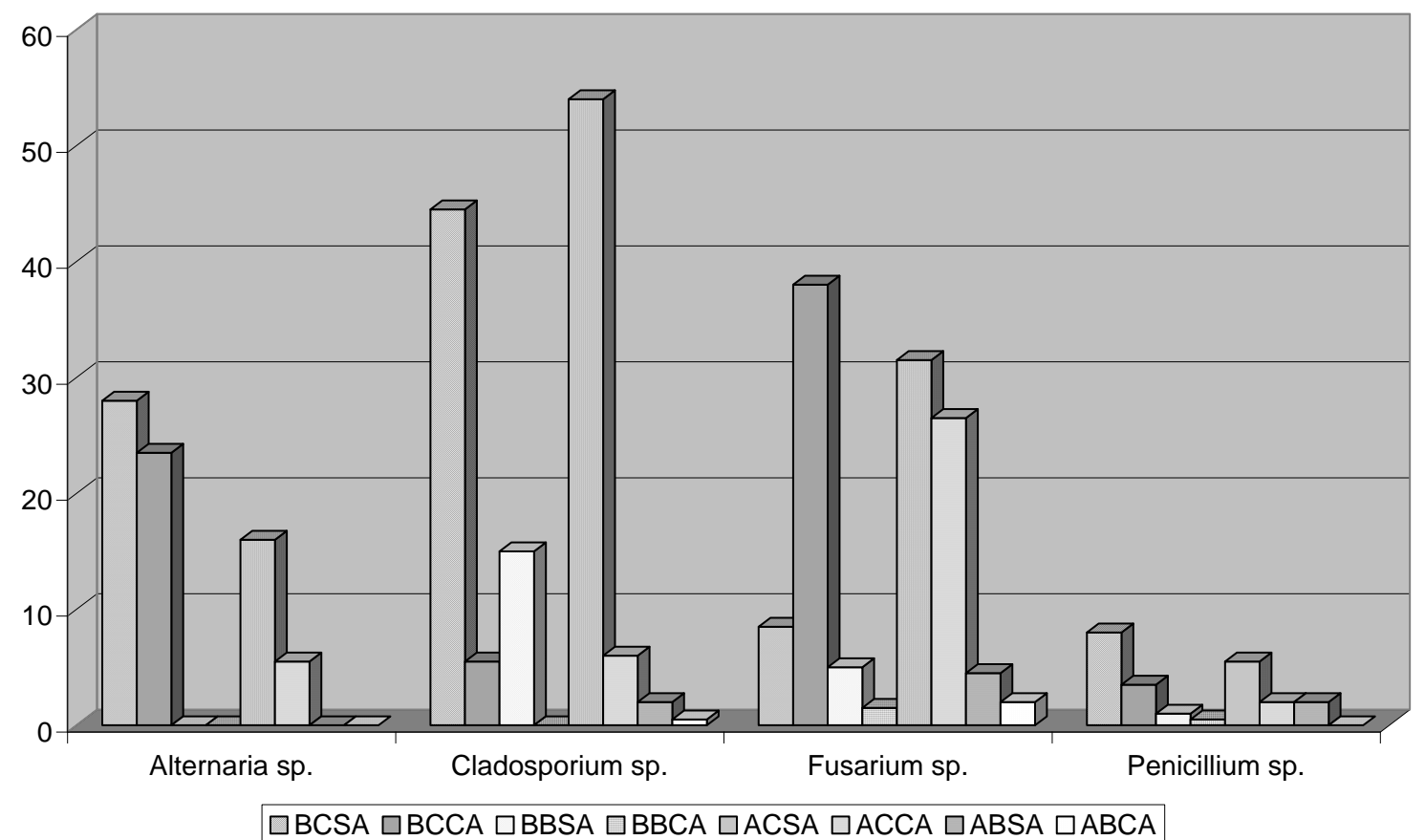

Os maiores percentuais de microrganismos foram observados em cafés provenientes dos solos predominantemente basálticos e café em coco, mas após o beneficiamento ocorreu uma redução.

Pasin et al. (2002) não detectou a presença de ocratoxina A em amostras por eles analisadas, mesmo quando detectada a presença do fungo Aspergillus ochraceus em percentuais médios de ocorrência de $50 \%$. No presente trabalho esse fungo atingiu valores máximos de $30 \%$ no tratamento basalto coco sem assepsia (BCSA).

A descoberta do composto 1,4-6 tricloroanisole (TCA) em cafés que apresentavam bebida rio (menor qualidade de bebida) e que sofreram a ação de Aspegillus niger e A. ochraceus estão relacionados com a má qualidade desse produto (AMORIM; MELLO, 1991). Os cafés aqui analisados foram classificados por meio da prova de xícara como café duro, que determina uma bebida de café que apresenta sabor acre, adstringente e áspero, porém sem apresentar paladares estranhos.

Sob crescente e diferentes teores de água, várias espécies de Aspergillus e Penicillium podem se manifestar. As primeiras espécies que se desenvolvem são as do gênero Aspergillus menos exigentes em água, após são espécies de Penicillium e, por último, as de Fusarium, estas exigindo maiores teores de água (CHRISTENSEN; KAUFHM, 1969 e 1974).

Os cafés avaliados no presente estudo estavam armazenados há seis meses e apresentaram percentuais de Penicillium sp. inferiores a 10\%, já os percentuais de Fusarium sp. e Alternaria sp. 
se mostraram elevados principalmente nos cafés em coco (Figura 2). Ao se comparar esses resultados com os citados por Braccini et al., (1999) que, ao quantificarem a incidência de fungos em sementes de café por períodos prolongados de tempo perceberam que fungos dos gêneros Fusarium sp. e Alternaria sp. eram predominantes no início do armazenamento, enquanto que os dos gêneros Aspergillus sp. e Penicillium sp. tinham sua população ampliada a partir do terceiro mês de armazenamento, pode-se observar que o café do presente estudo por ter sido armazenado sob condições controladas de temperatura e umidade em câmara fria e seca não ofereceu condições de aumento da população fúngica.

Os gêneros de fungos identificados no presente estudo estão dentre as mais comuns e versáteis espécies de fungos presentes em ambientes de pós-colheita e armazenamento. Eles podem tolerar e se desenvolver sob diferentes condições do ambiente, e são de difícil eliminação total com emprego de métodos convencionais de secagem e armazenamento.

\title{
4. Conclusão
}

Muitos microrganismos foram encontrados durante a análise: Alternaria sp., Aspergillus sp., Aspergillus niger, Aspergillus ochraceus, Aspergillus flavus e Colletotrichum sp., Penicillium sp., Fusarium sp. e Alternaria $s p$. Os cafés colhidos em solos basálticos apresentaram-se mais colonizados por microrganismos. Práticas como o beneficiamento e a assepsia dos grãos podem reduzir a incidência de microrganismos.

\section{Agradecimentos}

Os autores agradecem a colaboração do Sr. Jose Aparecido Rocha no desenvolvimento da pesquisa.

\begin{abstract}
The contamination of coffee grains for microorganisms can compromise a lot the coffee beverage quality; being with that very important to evaluate this product qualitatively. The purpose of the present study was identifying the microorganisms associated to the fruits of coffee in coconut and benefited ones harvested in farmings installed in soils originated of the basalt and the Caiuá sandstone. The filter paper, Blotter Test method was used and the fungi were identified by morphologic characteristics observed on stereoscopic and optical microscopes. The tracing used was the entirely casualized in factorial scheme $(2 \mathrm{x} 4)$ two soils (basaltic $\mathrm{x}$ arenaceous soils) $\mathrm{x}$ four processes (benefited and coconut, both with and without asepsis), totalizing eight treatments. For each treatment it was evaluated 10 repetitions of 20 seeds each. In the samples deriving from soils of basaltic origin it was observed greater amounts of Alternaria sp., Aspergillus sp., Aspergillus niger, Aspergillus ochraceus, Aspergillus flavus and Colletotrichum sp. The only microorganism that had prevalence for coffees originated of arenaceous soil was the Rhizoctonia sp. In a general
\end{abstract}


way, the processing and the asepsis of the seeds with sodium hypochlorite at $0,5 \%$ for one minute, reduced the incidence of microorganisms.

Key-words: Coffea arabica; cherry coffee; filamentous fungi.

\section{Referências}

AMORIM , H. V.; MELLO, M. Significance of enzymes in non alcoholic coffee beverage. In: BARNETT, H. L. \& HUNTER, B. B. Illustrated genera of imperfect fungi. 3.ed. Minneapolis: Burgess Publishing, 1972. 241p.

BITANCOURT, A. A. O tratamento das cerejas de café para melhorar a bebida. O Biológico, São Paulo, v.23, n.1, p.1$11,1957$.

BRACCINI, A. L.; SCAPIM, C. A.; BRACCINI, M. C. L.; ANDRADE, C. A B.; FILHO, P. S. V. Incidência de microrganismos em sementes de café robusta durante o armazenamento. Bragantia, Campinas, v.58, n.2, p.305-315, 1999.

CAMARGO, R. Cultura cafeeira: visando qualidade. São Paulo: s/ed., 1936.

CARVALHO, V. D. Cafeicultura empresarial: produtividade e qualidade - qualidade do café. Lavras: Universidade Federal de Lavras - Fundação de Apoio ao Ensino, Pesquisa e Extensão, 1997. 73 p.

CHALFOUN, S. M.; CARVALHO, V. L. Efeito de microrganismos na qualidade da bebida do café. Informe Agropecuário, Belo Horizonte, v.18, n.1, p.21-26, 1997.

CHRISTENSEN, C. M.; KAUFMANN, H. H. Grain storage: role of fungi in quality loss. Minneapolis: University of Minnesota Press, 1969.

CHRISTENSEN, C. M.; KAUFMANN, H. H. Microflora. In: CHRISTENSEN, C. M. Storage of cereal grains and their products. Minnesota: American Association of Cereal Chemists, 1974. p. 158-192.

KRUG, H. P. Cafés duros III. Relação entre a porcentagem de microrganismos e qualidade do café. Revista do Instituto do Café, São Paulo, v.27, n.163, p.1827-1831, 1941.

LACEY, J. Aspergilli in Feeds and Seeds. In: POWELL, K. A; RENWICK, A.; PEBERDY, J. F. eds. The Genus Aspergillus: from taxonomy and genetics to industrial application. New York: Plenum, 1994. 380p.

MITIDIERI, F. J. Nota técnica. Diário Oficial [da] República Federativa do Brasil, Brasília, 10 ago. 2007, n.154, Sessão 1. Disponível em: 〈http://www.in.gov.br/ materias/pdf/do/secao1/10_08_2007/do1-4.pdf〉. Acesso em: 27 dez. 2007.

NEERGAARD, P. Seed pathology. London: Mac Millan Press, v.2, 1977. 1191p.

PASIN, L. A. A. P.; ABREU, M. S. de, CHALFOUN, S. M.; PÁDUA, T. R. P. de. Efeito de micronutrientes na população fúngica associada a grãos de café (Coffea arabica L.). Ciência agrotecnologia, Lavras, v.26, n.5, p.918-926, 2002.

PEREIRA, R.T.G. Influência de Cladosporium cladosporioides na qualidade da bebida do café. 2002. Dissertação (Mestrado em Fitopatologia) - Universidade Federal de Lavras, Lavras. 42p.

PIMENTA, C. J.; CHALFOUN, S. M. Composição microbiana associada ao café em coco e beneficiado colhido em diferentes estádios de maturação. Ciência agrotecnologia, Lavras, v.25, n.3, p.677-682, 2001.

PIMENTA, C. J.; VILELLA, E. R. Qualidade do Café (Coffea arabica L.), lavado e submetido à diferentes tempos de amontoa no terreiro. Revista Brasileira de Armazenamento, Viçosa, especial, n.2, p.3-10, 2001.

SILVA, C. F.; BATISTA, L. R.; ABREU, L. M.; DIAS, E. S.; SCHWAN, R. F. Succession of bacterial and fungal communities during natural coffee (Coffea arabica) fermentation. Food Microbiology, London, v.25, n.8, p.951-957, 2008. doi:10.1016/j.fm.2008.07.003. 


\section{Dados dos autores:}

Nome completo: Carla Adriana Pizarro Schmidt

Filiação institucional: UTFPR - Campus Medianeira

Departamento: COENP

Função ou cargo ocupado: Professor de Ensino Básico, Técnico e Tecnológico

Titulação: Doutora

Endereço: Caixa Postal 1019, Medianeira - PR, CEP 85884-000

Telefones para contato: (045) 3264-6932

e-mail: carlaschmidt@utfpr.edu.br

Nome completo: Édson Miglioranza

Filiação institucional: Universidade Estadual de Londrina

Departamento: CCA

Função ou cargo ocupado: Professor - Diretor de Pesquisa da Pró-Reitoria de Pesquisa e Pós-

Graduação

Titulação: Pós Doutor

Endereço: Campus Universitário - Cx. Postal 6001 - CEP 86051-990 - Londrina-PR

Telefones para contato: (43) 3371-5985

e-mail: emiglior@uel.br

Nome completo: Martin Homechin

Filiação institucional: Universidade Estadual de Londrina

Departamento: CCA

Função ou cargo ocupado: Professor

Titulação: Doutor

Endereço: Campus Universitário - Cx. Postal 6001 - CEP 86051-990 - Londrina-PR

Telefones para contato: (43) 3371-4775

e-mail:deptagro@uel.br 